\title{
Morphological, Pathogenic, and Molecular Characterization of Alternaria Isolates Associated with Alternaria Late Blight of Pistachio
}

\author{
Barry M. Pryor and Themis J. Michailides
}

Department of Plant Pathology, University of California-Davis, Kearney Agricultural Center, Parlier 93648. Current address of B. M. Pryor: Department of Plant Pathology, University of Arizona, Tucson 85721. Accepted for publication 11 December 2001.

\begin{abstract}
Pryor, B. M., and Michailides, T. J. 2002. Morphological, pathogenic, and molecular characterization of Alternaria isolates associated with Alternaria late blight of pistachio. Phytopathology 92:406-416.

Alternaria isolates were obtained from various pistachio tissues collected in five orchards in California. For all isolates, morphological characteristics of the colony and sporulation apparatus were determined and compared with those of representative isolates of A. alternata, A. tenuissima, A. arborescens, and A. infectoria. A selection of the pistachio isolates and the representative Alternaria isolates were evaluated for pathogenicity to pistachio. Molecular characteristics of these isolates were determined using random amplified polymorphism DNA (RAPD) analysis, polymerase chain reaction restriction fragment length polymor-

Based on morphological characteristics, the pistachio isolates were grouped as identical or very similar to either A. alternata, A. tenuissima, $A$. arborescens, or $A$. infectoria. Isolates from the alternata, tenuissima, and arborescens species-groups were pathogenic to pistachio and no significant differences in pathogenicity were observed. Isolates from the infectoria species-group were only weakly pathogenic to pistachio. Based on cluster analysis of RAPD and PCR-RFLP data, three distinct clusters were evident; the infectoria cluster, the arborescens cluster, and a combined alternata/tenuissima cluster. Based on analysis of ITS sequence data, the infectoria species-group was phylogenetically distinct from the other species-groups. Isolates of the alternata, tenuissima, and arborescens species-groups comprised a monophyletic clade in which the three species-groups could not be further resolved.
\end{abstract} phism (PCR-RFLP) analysis of nuclear intergenic spacer rDNA, and sequence analysis of nuclear internal transcribed spacer (ITS) rDNA.
Additional keywords: DNA fingerprinting, Pistacia vera, taxonomy.
Alternaria late blight of pistachio is one of the most common fungal diseases of pistachio in California, and affects both foliage and fruit. On foliage, the disease is characterized by the development of large necrotic lesions that eventually coalesce and consume the entire leaf. The lesions generally are black in the center due to the abundant production of fungal spores and typically are surrounded by a chlorotic halo. Infection of leaves can occur in spring and summer but are generally quiescent $(14,16)$. Symptoms usually develop in late summer and fall and, under optimal conditions, can defoliate the tree. On fruit, the disease is characterized by the development of small necrotic spots on the hull of immature nuts. These lesions are typically surrounded by a red halo. As the nuts develop, one or few of these lesions expand and can penetrate the hull, resulting in shell staining of the nut underneath and a reduction in nut quality after invasion of the kernel.

Previous research has concluded that Alternaria alternata is the causal agent of late blight of pistachio $(7,13,38)$. However, most Alternaria spp., including A. alternata, exhibit considerable morphological plasticity that is dependent upon cultural conditions of substrate, temperature, light, and humidity (17,29). In addition, within any culture, there is a considerable range of variation in conidium morphology in regard to size, shape, septation, color, and ornamentation that is dependent upon conidium age (29). Moreover, there are several small-spored catenulate Alternaria spp. with morphological characteristics that overlap those of $A$. alternata; the most commonly known are A. tenuissima and $A$. infectoria. Further complicating the taxonomy of this group of fungi is the presence of numerous isolates with intermediate characteristics that do not clearly segregate into recognized

Corresponding author: B. M. Pryor; E-mail address: bmpryor@ag.arizona.edu

Publication no. P-2002-0212-02R

(C) 2002 The American Phytopathological Society species (33). Thus, differentiating these fungi can be difficult for those not familiar with the specific morphological characteristics that separate these species, and it has been suggested that these fungi, in particular A. alternata, are frequently misidentified $(25,29)$.

In addition to morphology, variation exists among small-spored catenulate Alternaria taxa in respect to host range. Examples of host-specific small-spored taxa include $A$. mali on apple, A. gaisen on pear, A. longipes on tobacco, A. alternata pathotype strawberry on strawberry, $A$. citri (pathotypes tangerine and rough lemon) on citrus, and A. alternata f. sp. lycopersici on tomato. As with $A$. tenuissima and $A$. infectoria, many of the conidium characteristics of these taxa overlap those of A. alternata, and some researchers have suggested that many of the host-specific taxa should be referred to as pathotypes or as formae speciales of A. alternata (19, 26). However, recent work under defined cultural conditions has revealed that host-specific taxa often have distinct morphological differences that are diagnostic, in particular, characteristics of the three-dimensional sporulation apparatus $(29,32)$. This approach has given rise to several newly described Alternaria spp. (31), or a reclassification of formerly described taxa, such as A. arborescens, formerly known as A. alternata f. sp. lycopersici (32).

Considering the diversity of conidium shapes and sizes among Alternaria spp. in general, there have been efforts in developing sub-generic groupings of species based upon similar conidium characteristics. Most recently, Simmons (29) organized the genus into 14 species-groups based upon characteristics of conidia and chain formation. In subsequent work with Alternaria isolates recovered from pear, Simmons and Roberts further advanced the species-group concept by referring to certain groups using a representative species, for instance, the alternata group, the tenuissima group, and the infectoria group (33). Additional species-groups discussed in other work include the arborescens, brassicicola, porri, and radicina groups $(21,25,30,33)$. Although the use of 
species-group designation does not resolve more definitive species boundaries within Alternaria, advantages of its use are that it organizes at the sub-generic level the morphologically diverse assemblage of Alternaria spp. and permits the generalized discussion of morphologically similar species without becoming overly restricted due to nomenclatural uncertainty. This has been particularly valuable in discussions of small-spored catenulate species.

With the advancement of molecular techniques, several studies have examined taxonomic relationships among small-spored catenulate Alternaria spp. using a variety of methods in an attempt to establish consensuses with contemporary morphological-based species. Analyses of DNA-DNA reassociation kinetics revealed high DNA homology among several small-spored host-specific Alternaria spp. and A. alternata, which suggests these species represent intraspecific taxa (9). Supporting these results, restriction fragment length polymorphism (RFLP) analyses using the $\lambda$ phage clone Alt1 as a hybridization probe were not able to differentiate small-spore host-specific Alternaria spp. from A. alternata (10). However, RFLP analyses using a fragment of the Alt1 clone were able to segregate small-spored Alternaria isolates from pistachio into three distinct groups, although critical morphological characterization of these isolates was not performed (4). Sequence analysis of the nuclear rDNA internal transcribed spacer (ITS) region has revealed variation (1 to 4 nucleotides [nts]) among small-spored Alternaria spp., but failed to resolve these taxa as phylogenetically distinct from A. alternata (11). However, random amplified polymorphism DNA (RAPD) analyses of $A$. alternata, A. tenuissima, A. infectoria, and small-spored hostspecific species revealed distinctive RAPD fragment patterns for all species, and cluster analysis did resolve these species into distinct clades, which suggests that these taxa constitute well-defined species (25). In summary, previous molecular studies have not produced a consensus on the genetic relationships among smallspored catenulate Alternaria spp., which underscores the controversial taxonomic status of this group of fungi.

The purpose of this work was to examine morphological diversity among Alternaria isolates from pistachio, to determine the temporal and spatial distribution of this diversity, and evaluate the pathogenicity of the different morphological types and their potential as causal agents of Alternaria late blight of pistachio. An additional objective of this project was to evaluate the phylogenetic relationships among Alternaria isolates from pistachio and representative isolates from the various small-spored catenulate species-groups using a variety of molecular techniques in an effort to further our understanding of the taxonomic status of these Alternaria spp.

\section{MATERIALS AND METHODS}

Collection of isolates. Isolates of Alternaria spp. were obtained from pistachio tissue collected in five orchards in California near the following urban areas: Stockton, Parlier, Hanford, Tulare, and Kettleman City. At most locations, isolates were obtained during three different periods of the 1999 growing season and from various pistachio (cv. Kerman) tissues: in spring, from orchard debris and from asymptomatic buds, flower clusters, and leaves; in summer, from orchard debris and from asymptomatic nuts and leaves; and in fall, from active late blight lesions on leaves. To obtain isolates from orchard debris, $10 \mathrm{~g}$ of plant material was placed in $500 \mathrm{ml}$ of sterile $\mathrm{H}_{2} \mathrm{O}$ and agitated on a rotary shaker for $30 \mathrm{~min}$. For each sample, $1 \mathrm{ml}$ of the wash solution was plated onto petri dishes containing acidified $(2.5 \mathrm{ml}$ of $25 \%$ [vol/vol] lactic acid per liter of agar) potato dextrose agar (PDA; Difco Laboratories, Detroit), and was spread evenly over the surface using a bent glass rod and petri plate turntable. Plates were incubated at $22^{\circ} \mathrm{C}$ under cool white fluorescent lights (F20T12/CW; Osram Sylvania, Danvers, MA) for 7 to 10 days. Approximately
40 putative Alternaria colonies were randomly selected from these plates and subcultured onto dishes containing PDA until pure cultures were obtained.

To obtain isolates from asymptomatic buds and flower clusters, plant tissue was placed in $0.56 \% \mathrm{NaOCl}$ (10\% Clorox bleach; The Clorox Company, Oakland, CA) for 30 to $60 \mathrm{~s}$. Individual buds and parts of flower clusters were then plated onto petri dishes containing acidified PDA and incubated for 3 to 5 days at $22^{\circ} \mathrm{C}$ under cool white fluorescent lights. Approximately 60 putative Alternaria colonies were subcultured onto dishes containing PDA until pure cultures were obtained.

To obtain isolates from latent infections in asymptomatic nuts and leaves, plant material was examined with the overnight freeze incubation technique (ONFIT) $(14,15)$. For the ONFIT, plant material was surface-disinfested in $70 \%$ ethanol for $15 \mathrm{~s}$, followed by $0.56 \% \mathrm{NaOCl}$ (with Tween 20 added at $0.5 \mathrm{ml} / \mathrm{liter}$ ) for $4 \mathrm{~min}$, and placed on paper towels in a laminar flow hood for $10 \mathrm{~min}$ to dry. Plant material was then placed on raised plastic mesh enclosed in clear plastic boxes $(23 \times 31 \times 10 \mathrm{~cm}$ [length $\times$ width $\times$ height]) (with lids) to which $200 \mathrm{ml}$ of deionized $\mathrm{H}_{2} \mathrm{O}$ was added underneath the mesh to maintain high humidity. Boxes were held at $-20^{\circ} \mathrm{C}$ for $24 \mathrm{~h}$ to freeze plant tissue, and incubated at $22^{\circ} \mathrm{C}$ under cool white fluorescent lights for 7 to 10 days. Approximately 80 putative Alternaria colonies that erupted from the nut or leaf tissue were randomly selected and subcultured onto dishes containing PDA until pure cultures were obtained.

To obtain isolates from active late blight lesions, leaves that had clearly delineated lesions were collected from the five orchards. A $5-\mathrm{mm}^{2}$ section was removed from the leading edge of the lesion and placed in $0.56 \% \mathrm{NaOCl}$ for 30 to $60 \mathrm{~s}$. Leaf sections were then plated onto petri dishes containing acidified PDA and incubated for 3 to 5 days at $22^{\circ} \mathrm{C}$ under cool white fluorescent lights. Approximately 150 putative Alternaria colonies were subcultured onto dishes containing PDA until pure cultures were obtained. Pure cultures confirmed to be Alternaria spp. were transferred to slants containing $10 \mathrm{ml}$ of $0.05 \times$ PDA $(1.2 \mathrm{~g}$ of potato dextrose broth [Difco Laboratories] and $15 \mathrm{~g}$ of Bacto agar [Difco Laboratories] per liter of $\mathrm{H}_{2} \mathrm{O}$ ) for storage at $5^{\circ} \mathrm{C}$.

Morphological characterization. For all isolates, morphological characteristics of the colony and sporulation apparatus were determined from single-spored colonies. To obtain single-spored colonies, isolates were initially transferred onto plastic petri dishes $(100 \times 15 \mathrm{~mm})$ containing $0.05 \times$ PDA and incubated in a lighted incubator without humidity control for 7 to 10 days at $22^{\circ} \mathrm{C}$. For consistent sporulation, dishes were kept $31 \mathrm{~cm}$ below cool white fluorescent bulbs and illuminated with $10 \mathrm{~h} / 14 \mathrm{~h}$ periods of light/dark. During light periods, the illumination intensity at the surface of the petri dishes was approximately 4,000 lx. After incubation, conidial suspensions were obtained by flooding dishes with $10 \mathrm{ml}$ of sterile $\mathrm{H}_{2} \mathrm{O}$ and dislodging conidia with a pipette tip. Three drops of conidial suspension were pipetted onto the surface of a petri dish containing water agar ( $15 \mathrm{~g}$ of Bacto agar per liter of $\mathrm{H}_{2} \mathrm{O}$ ), and the plates were shaken horizontally on a lab bench to disperse the drops containing conidia. The water agar dishes were incubated for 2 to $4 \mathrm{~h}$ at $22^{\circ} \mathrm{C}$ to allow for conidia germination, and germinating conidia were used as inoculum for continued morphological characterization of isolates.

To characterize isolates by colony morphology, single germinating conidia were transferred to petri dishes containing PDA. Dishes were incubated at $22^{\circ} \mathrm{C}$ in darkness for 10 days. After incubation, cultures were examined for colony color, colony margin, colony texture, and the development of pigments or crystals in the agar medium. Colony color was determined according to Ridgway's color standards (24). Colony texture was determined according to descriptions by Nobles (20).

To characterize isolates by sporulation habit, single germinating conidia were transferred to petri dishes containing $0.05 \times$ PDA. 
Dishes were incubated for 7 days in a lighted incubator as previously described. After incubation, cultures were examined at $\times 40$ to $\times 100$ magnification with a dissecting microscope and substage illumination for characteristics of the sporulation apparatus, including length of conidial chains, presence of elongated secondary conidiophores, and manner by which branching of conidial chains (if present) occurred.

The colony and sporulation characteristics of representative cultures of A. alternata, A. tenuissima, A. arborescens, and A. infectoria (EGS 34-016, EGS 34-015, EGS 39-128, and EGS $27-$ 193, respectively; Mycological Services, Crawfordsville, IN) were also determined and compared with those of the pistachio isolates. Morphological characterization of these isolates was performed in the same manner as for the pistachio isolates.

Pathogenicity tests. Selected pistachio isolates $(n=30)$ that represented a range of morphological types and the representative Alternaria spp. were tested for pathogenicity to pistachio leaves. Tests were conducted on detached pistachio leaves of cv. Kerman obtained from young pistachio trees (approximately $2.5-\mathrm{cm}$ trunk diameter) grown in greenhouses. For each isolate tested, three fully expanded leaves were placed singly on wire mesh platforms resting in plastic boxes $(23 \times 31 \times 10 \mathrm{~cm}$ [length $\times$ width $\times$ height]), and water was added to each box and underneath the wire platform to a depth of $1 \mathrm{~cm}$. Tests were conducted on unwounded and wounded leaves. For wounded leaf assays, each leaf was slightly wounded on the midrib with a razor blade prior to inoculation. To inoculate leaves, $20 \mu \mathrm{l}$ of a conidial suspension (obtained as described before from a 7-day-old fungal culture on $0.05 \times$ PDA, and diluted to $10^{3}$ conidia per $\mathrm{ml}$ of $\mathrm{H}_{2} \mathrm{O}$ ) was placed on each leaf or wound. The plastic boxes were covered to maintain high humidity and were incubated at $20^{\circ} \mathrm{C}$ for 7 days. After incubation, resulting lesions were scored on a 4-point rating system: $1=$ no lesion, $2=$ lesions $<1 \mathrm{~mm}$ in diameter, $3=$ lesions 1 to $5 \mathrm{~mm}$ in diameter, and $4=$ lesions $>5 \mathrm{~mm}$ in diameter (Fig. 1), and lesion scores for each isolate were averaged. These experiments were conducted two times.

In addition to Alternaria isolates, three isolates each of four other fungal genera commonly isolated from pistachio in this study, Stemphylium, Fusarium, Cladosporium, and Epicoccum spp., were also tested for pathogenicity. Pathogenicity tests for these fungi were conducted in the same manner as for the Alternaria isolates.

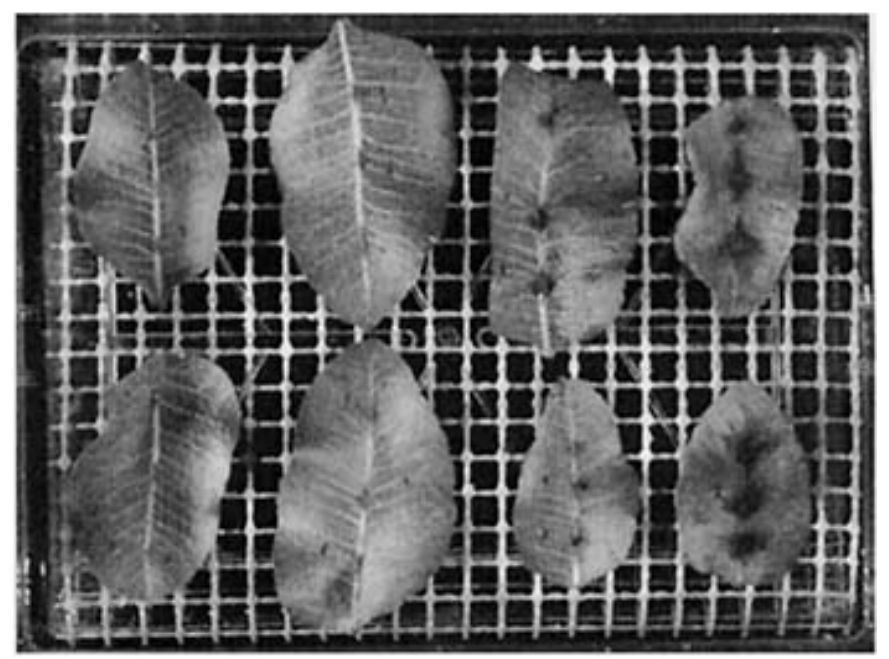

Fig. 1. Disease ratings used in detached pistachio leaf assays to assess pathogenicity of fungi recovered from pistachio and representative Alternaria spp. Rating scale for lesion development on 'Kerman' pistachio leaves (three lesions per leaf) was as follows in leaves left to right: $1=$ no lesion development; $2=$ lesions $<1$-mm diameter; $3=$ lesions 1 - to 5 -mm diameter; and $4=$ lesions $>5$-mm diameter.
Molecular analyses. Selected pistachio isolates $(n=30)$ that represented a range of morphological types and the representative isolates were examined for molecular characteristics by three different approaches: RAPD analysis, polymerase chain reaction (PCR)-RFLP analysis, and ITS sequence analysis. Genomic DNA used in these analyses was obtained from fungi grown in liquid culture according to a previously established protocol (21).

For RAPD analysis, eight primers from Operon random primer set A (A01, A03, A08, A10, A12, A14, A16, and A20; Operon Technologies, Alameda, CA) were used to generate RAPD fragments from genomic DNA. RAPD reactions were carried out in a 50- $\mu$ PCR reaction mixture containing $20 \mathrm{ng}$ of DNA, $0.5 \mathrm{mM}$ primer, $0.25 \mathrm{mM}$ each dNTP, $2.5 \mathrm{mM} \mathrm{MgCl}_{2}$, and 1.0 unit of AmpliTaq DNA polymerase in 1× AmpliTaq PCR buffer II (Perkin-Elmer Applied Biosystems, Foster City, CA). The PCR was carried out in a thermal cycler (Model 480; PE Applied Biosystems) programmed for the following conditions: $94^{\circ} \mathrm{C}$ for $1 \mathrm{~min}, 34^{\circ} \mathrm{C}$ for $1.5 \mathrm{~min}$, and $72^{\circ} \mathrm{C}$ for $2 \mathrm{~min}$ for 45 cycles. PCR products were resolved in $1 \%$ agarose gels in Tris-borate-EDTA (TBE) buffer and visualized by UV illumination after staining in ethidium bromide (27).

For PCR-RFLP analysis, five restriction enzymes (RsaI, MboI, HinfI, HaeIII, and AluI; Promega Corporation, Madison, WI) were used to digest PCR-amplified nuclear intergenic spacer (IGS) rDNA. IGS fragments were generated from genomic DNA using the conserved primers CNL12 and CNS1 (3). PCR amplification using total genomic DNA was carried out in a $50-\mu$ l reaction mixture containing $20 \mathrm{ng}$ of DNA, $0.5 \mathrm{mM}$ of each primer, $0.25 \mathrm{mM}$ each dNTP, $2.5 \mathrm{mM} \mathrm{MgCl}$, and 1.0 unit of AmpliTaq DNA polymerase in $1 \times$ AmpliTaq PCR buffer II. PCR was carried out in a thermal cycler (Model 480) programmed for the following parameters: $94^{\circ} \mathrm{C}$ for $1 \mathrm{~min}, 60^{\circ} \mathrm{C}$ for $1.5 \mathrm{~min}$, and $72^{\circ} \mathrm{C}$ for $2 \mathrm{~min}$ for 35 cycles. PCR-amplified DNA fragments were resolved in $1.0 \%$ agarose gels in TBE buffer and visualized by UV illumination after staining in ethidium bromide. Restriction digestions were carried out using $2 \mu \mathrm{l}$ of PCR product in $10-\mu$ l reaction mixtures for $2 \mathrm{~h}$ according to enzyme manufacturer's recommendations. Digestion products were resolved in $1 \%$ agarose gels in TBE buffer and visualized by UV illumination after staining in ethidium bromide.

RAPD and PCR-RFLP analyses were performed twice to confirm reproducibility of amplification and digestion products. For

TABLE 1. Key used to classify small-spored Alternaria isolates recovered from pistachio into four species-groups based on catenulation characteristics ${ }^{\mathrm{a}}$

1a Elongated secondary conidiophores from distal terminal conidium cells are common and are often one to three times the length of the conidium body................................... infectoria species-group

1b Elongated secondary conidiophores from distal terminal conidium cells are common or uncommon and are generally less than the length of the conidium body.

2a Conidial chains branch almost exclusively in a sympodial manner through the short elongation of secondary conidiophores from distal terminal conidium cells.................... arborescens species-group

2b Conidial chains branch in a sympodial manner through the short elongation of secondary conidiophores from distal terminal conidium cells and in a lateral manner through the short elongation of secondary conidiophores from median or basal conidium cells................ 3

3a Conidial chains 6 to 14 conidia in length with abundant secondary and tertiary branches 2 to 8 conidia in length......... alternata species-group

3b Conidial chains 6 to 18 conidia in length with occasional secondary branches 1 to 4 conidia in length............. tenuissima species-group

${ }^{a}$ For consistent production of diagnostic characteristics, cultures were grown from single spores on $0.05 \times$ potato dextrose agar in plastic petri dishes $(100 \times 15 \mathrm{~mm})$. Dishes were incubated without humidity control for 7 days at $22^{\circ} \mathrm{C}$ with cool white fluorescent illumination with a $10 / 14 \mathrm{~h}$ light/dark cycle. Cultures were placed $31 \mathrm{~cm}$ below lights, which resulted in an illumination intensity at the surface of the dishes of approximately 4,000 lx. 
both analyses, product sizes were determined with a digital imaging system (IS-1000; Alpha Innotech Co., San Leandro, CA). For RAPD analysis, all reproducible products between 500 and $2,500 \mathrm{bp}$ were scored with no correction for band intensity. For PCR-RFLP analysis, all reproducible products were scored. The presence or absence of a given RAPD or PCR-RFLP fragment was determined for each isolate, and a binary matrix was constructed for each data set and for the combined data set. Cluster analysis of the data matrix was performed by the unweighted pairgroup method with arithmetic mean using numerical taxonomy and multivariate analysis system software (NTSYS-pc, version 1.80; Exeter Software, Setauket, NY).

For ITS sequence analysis, the nuclear rDNA ITS region, including ITS1 and ITS2 and the 5.8S ribosomal gene, was amplified using PCR and primers ITS5 and ITS4 (39). The PCR was performed with the same conditions as was the PCR for IGS amplification. PCR-amplified DNA fragments were resolved in $1.0 \%$ agarose gels in TBE buffer, and DNA was visualized by ethidium bromide staining and UV illumination. DNA was recovered from agarose with a silica matrix (GeneClean; Bio 101, Inc., Vista, CA) according to manufacturer's recommendations.

DNA sequences of PCR-amplified fragments were determined with a DNA sequencer using either dRhodamine terminator or big dye terminator chemistry (ABI Prism 377; Perkin-Elmer/ABI). Primers used for sequencing were the same as those used to direct the amplification of the given DNA fragment. The sequences of both strands of each fragment were determined for sequence confirmation.

The ITS sequences of the pistachio isolates and the representative isolates, in addition to those from 19 other Alternaria, Ulocladium, and Stemphylium spp. obtained from GenBank, were aligned with the PILEUP program of the GCG sequence analysis software Package (version 9.1; Genetics Computer Group, Madison, WI). Sequences from Bipolaris tetramera and Exserohilum pedicillatum that were also obtained from GenBank were used as outgroups. In some cases, manual adjustments of sequence alignments were performed using the data editor program of MacClade phylogenetic software. Phylogenetic analyses were performed using programs contained in phylogenetic analysis using parsimony (PAUP) software. Phylogenetic trees were constructed using maximum parsimony and distance methods. For parsimony analysis, heuristic searches for the most parsimonious trees were conducted using random step-wise addition and branch swapping by tree bisection-reconnection. Sequence gaps were not recoded and were treated as missing data. For distance analysis, the neighbor-joining method was performed using Kimura 2-parameter

TABLE 2. Recovery of isolates of four Alternaria species-groups from pistachio in California at three times during the season and from various host tissues

\begin{tabular}{lccccccc}
\hline & \multicolumn{7}{c}{ Tissue $^{\mathrm{a}}$} \\
\cline { 2 - 6 } $\begin{array}{l}\text { Sample } \\
\text { time }\end{array}$ & Group $^{\mathrm{b}}$ & $\begin{array}{c}\text { Orchard } \\
\text { debris }\end{array}$ & Bud & $\begin{array}{c}\text { Flower } \\
\text { cluster }\end{array}$ & Nut & Leaf & $\begin{array}{c}\text { Leaf } \\
\text { lesion }\end{array}$ \\
\hline May & AAL & 10 & 11 & 4 & 3 & 8 & - \\
& ATE & 7 & 12 & 6 & 0 & 9 & - \\
& AAR & 8 & 6 & 8 & 1 & 8 & - \\
\multirow{5}{*}{ August } & AIN & 0 & 1 & 4 & 0 & 0 & - \\
& AAL & 5 & - & - & 7 & 8 & - \\
& ATE & 3 & - & - & 6 & 12 & - \\
\multirow{5}{*}{ September } & AAR & 3 & - & - & 4 & 6 & - \\
(Harvest) & AIN & 0 & - & - & 0 & 2 & - \\
& AAL & - & - & - & - & - & 58 \\
& ATE & - & - & - & - & - & 51 \\
& AAR & - & - & - & - & - & 35 \\
\hline
\end{tabular}

${ }^{a}$ Values are the number of isolates recovered.

b Alternaria species-group designations: $\mathrm{AAL}=$ alternata, $\mathrm{ATE}=$ tenuissima, $\mathrm{AAR}=$ arborescens, and AIN $=$ infectoria. distances. For each analysis, 1,000 bootstrap replicates were performed to assess the statistical support for each tree.

\section{RESULTS}

Morphological characterization. A collection of 308 Alternaria isolates was collected from the five sample sites. Based on characteristics of single-spored colonies, all pistachio isolates could be grouped into approximately four colony types. Group 1 consisted of colonies that were lettuce green to olive green and usually had a prominent ( 2 to $5 \mathrm{~mm}$ ) white margin. Colony texture was felty to woolly. This group did not produce diffusible pigments, but $42 \%$ (48/114) of the isolates produced whitish crystals in the agar medium underneath the mycelial mat. Isolates typically produced colonies over $70 \mathrm{~mm}$ in diameter after 7 to 10 days. These characteristics were most similar to those of the A. alternata representative culture.

Group 2 isolates produced colonies that were pale olive gray to olive gray, often with a very thin (1 to $2 \mathrm{~mm}$ ) white margin. Colony texture was generally woolly to cottony. This group did not produce diffusible pigments, although $61 \%$ (65/106) of all isolates produced whitish crystals in the agar medium underneath the mycelial mat and some produced crystals in great abundance. Isolates typically produced colonies 50 to $70 \mathrm{~mm}$ in diameter after 7 to 10 days. These characteristics were most similar to those of the A. tenuissima representative culture.

Group 3 isolates produced colonies that were typically dark olive gray to iron gray to castor gray in color. The colony margin of these isolates was often wavy or torn. Colony texture was generally felty to woolly. Colony growth was generally much reduced ( $<50 \mathrm{~mm}$ after 7 to 10 days), and 95\% (75/79) of isolates produced a diffusible pale orange pigment and abundant crystals in the agar medium underneath the mycelial mat. These charac-

TABLE 3. Source of pistachio isolates used for pathogenicity and molecular characterizations

\begin{tabular}{|c|c|c|c|c|}
\hline Isolate & Location $^{\mathrm{a}}$ & Tissue & Sample time & Group $^{b}$ \\
\hline A039 & $\mathrm{H}$ & Flower & May & AAL \\
\hline A100 & $\mathrm{P}$ & Nut & August & AAL \\
\hline A112 & $\mathrm{K}$ & Nut & August & AAL \\
\hline A142 & $\mathrm{H}$ & Leaf & August & AAL \\
\hline A150 & $\mathrm{H}$ & Leaf & August & AAL \\
\hline A154 & $\mathrm{P}$ & Leaf lesion & September & AAL \\
\hline A204 & $\mathrm{T}$ & Leaf lesion & September & AAL \\
\hline A59 & K & Flower & May & ATE \\
\hline A68 & $\mathrm{H}$ & Flower & May & ATE \\
\hline A134 & K & Nut & August & ATE \\
\hline A340 & $\mathrm{P}$ & Leaf & August & ATE \\
\hline A 350 & $\mathrm{P}$ & Leaf & August & ATE \\
\hline A451 & $\mathrm{S}$ & Leaf lesion & September & ATE \\
\hline A5E6 & $\mathrm{T}$ & Leaf lesion & September & ATE \\
\hline A5E9 & $\mathrm{T}$ & Leaf lesion & September & ATE \\
\hline A61 & $\mathrm{K}$ & Flower & May & AAR \\
\hline A67 & $\mathrm{H}$ & Flower & May & AAR \\
\hline A101 & $\mathrm{H}$ & Nut & August & AAR \\
\hline A133 & $\mathrm{K}$ & Nut & August & AAR \\
\hline A143 & $\mathrm{H}$ & Leaf & August & AAR \\
\hline A151 & $\mathrm{H}$ & Leaf & August & AAR \\
\hline A153 & $\mathrm{P}$ & Leaf & August & AAR \\
\hline A181 & $\mathrm{H}$ & Leaf & August & AAR \\
\hline A186 & $\mathrm{H}$ & Leaf lesion & September & AAR \\
\hline A202 & $\mathrm{H}$ & Leaf lesion & September & AAR \\
\hline $\mathrm{A} 3 \mathrm{~A} 2$ & $\mathrm{~T}$ & Leaf lesion & September & AAR \\
\hline A3A3 & $\mathrm{S}$ & Leaf lesion & September & AAR \\
\hline A60 & $\mathrm{K}$ & Flower & May & AIN \\
\hline A65 & $\mathrm{K}$ & Flower & May & AIN \\
\hline A91 & $\mathrm{H}$ & Nut & August & AIN \\
\hline
\end{tabular}

a Location designations are as follows: $\mathrm{H}=$ Hanford, $\mathrm{K}=$ Kettleman City, $\mathrm{P}=$ Parlier, $\mathrm{S}=$ Stockton, and $\mathrm{T}=$ Tulare.

b Alternaria species-group designations: AAL = alternata, $\mathrm{ATE}=$ tenuissima, $\mathrm{AAR}=$ arborescens, and $\mathrm{AIN}=$ infectoria. 
teristics were most similar to those of the A. arborescens representative culture.

Group 4 isolates produced colonies that were either white to pale gray or apricot orange in color. Colonies generally had a cottony texture. Tufts of sterile (nonsporulating) white hyphae were present at the center of the colony. The undersurfaces of the colonies were usually orange or dark orange. No diffusible pigments or crystals were produced by these isolates. Isolates typically produced colonies over $70 \mathrm{~mm}$ in diameter after 7 to 10 days. These characteristics were most similar to those of the $A$. infectoria representative culture, with the exception of the orange pigmentation.

Based upon sporulation habit of single-spored colonies, all pistachio isolates were grouped into four sporulation types. Group A isolates were characterized by the formation of conidial chains 6 to 14 conidia in length and the development of numerous secondary, and occasionally tertiary, chains 2 to 8 conidia in length. Chain branching occurred in a sympodial manner through the elongation of secondary conidiophores from distal terminal conidial cells and subsequent conidium formation, or through the lateral growth of secondary conidiophores from median or basal conidial cells and subsequent conidium formation. Conidia were typically ovate in shape, and the development of apical extensions was minimal. These characteristics were most similar to those of the $A$. alternata representative culture. Based upon these results, these isolates were placed in the alternata species-group.

Group B isolates were characterized by the formation of conidial chains 6 to 18 conidia in length and the uncommon occurrence of secondary chains 1 to 4 conidia in length. Chain branching occasionally occurred in a sympodial manner through the elongation of secondary conidiophores from distal terminal conidial cells and subsequent conidium formation, but more typically through the lateral growth of secondary conidiophores from median or basal conidial cells and subsequent conidium formation. Conidia were typically ovate to obclavate in shape with many conidia developing distinctive apical extensions up to the length of the conidium body. Some isolates had conidia with 1 to 2 median transepta that were much more distinctive than proximal or distal transepta. These characteristics were most similar to those of the A. tenuissima representative culture. Based upon these results, these isolates were placed in the tenuissima species-group.

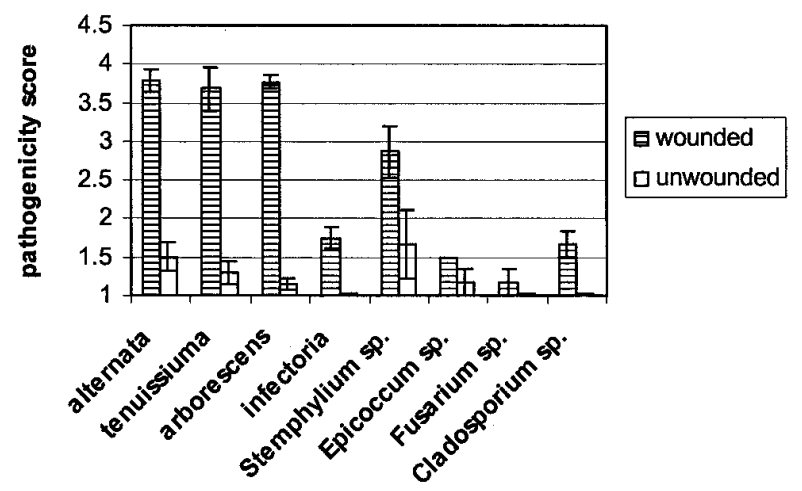

Fig. 2. Pathogenicity of Alternaria isolates from the alternata $(n=8)$, tenuissima $(n=9)$, arborescens $(n=13)$, and infectoria $(n=4)$ speciesgroups and other fungi based on results from detached pistachio leaf assays. Pathogenicity score was based on lesion development following inoculation of wounded and unwounded pistachio leaves using the following rating scale: 1 = no lesion development; 2 = lesions $<1$-mm diameter; $3=$ lesions 1 - to 5-mm diameter; and $4=1$ lesions $>5-\mathrm{mm}$ diameter. For each Alternaria species-group, the isolates tested included one isolate that was a representative culture for that group and was not obtained from pistachio, whereas all other isolates were obtained from various pistachio tissues. For the other fungal genera, the isolates tested $(n=3)$ were obtained from various pistachio tissues. For each fungal group, the pathogenicity score represents the average of the individual scores for all isolates tested.
Group $\mathrm{C}$ isolates were characterized by the formation of conidial chains 2 to 6 (rarely 8) conidia in length and the formation of numerous secondary, tertiary, and quaternary chains 2 to 4 conidia in length. Chain branching almost exclusively occurred in a sympodial manner through the elongation of secondary conidiophores from distal terminal conidial cells and subsequent conidium formation. Some isolates commonly developed long primary conidiophores ( 150 to $200 \mu \mathrm{m})$ before the initiation of conidial chains. Conidia were typically ovate in shape, and the development of apical extensions was minimal. These characteristics were most similar to those of the A. arborescens representative culture. Based upon these results, these isolates were placed in the arborescens species-group.

Group D isolates were characterized by the formation of conidial chains 2 to 8 conidia in length and the formation of numerous secondary, tertiary, and quaternary chains 2 to 4 conidia in length. Chain branching almost exclusively occurred in a sympodial manner through the extensive elongation of secondary conidiophores from distal terminal conidial cells and subsequent conidium formation. Secondary conidiophores were often one to three times the length of conidia. Conidia were typically ovate to obclavate in shape, with many conidia developing distinctive apical extensions up to, and occasionally greater than, the length of the conidium body. These characteristics were most similar to those of the $A$. infectoria representative culture. Based upon these results, these isolates were placed in the infectoria species-group. The key used to place pistachio isolates into one of the four sporulation groups is given in Table 1.

Group A isolates exhibited colony morphology of group 1 and group B isolates exhibited colony morphology of group 2. Group $\mathrm{C}$ isolates generally exhibited colony morphology of group 3 isolates, but $12 \%$ exhibited colony morphology more similar to group 1 isolates. Group D isolates exhibited colony morphology of group 4 isolates.

In examining the recovery of the four species-groups by time of year and location, no conclusive correlations could be made between any of the groups and a particular orchard or season, i.e., all groups could be found in all orchards at all times of the year (Table 2). With the exception of isolates in the infectoria speciesgroup, which was most commonly recovered from flower clusters and only occasionally recovered from other pistachio tissues, isolates from each species-group could be recovered from all pistachio tissues; from washing of orchard debris, from buds and flower clusters, as latent infections in nuts and leaves, and from active late blight lesions. In some instances, isolates from all four species-groups could be recovered from a single leaf.

Pathogenicity tests. Pathogenicity tests conducted with selected Alternaria isolates from pistachio (Table 3) and representative isolates on unwounded leaves failed to induce substantial lesion development for any of the isolates tested (Fig. 2). In contrast, pathogenicity tests conducted on wounded leaves resulted in significant lesion development for many of the Alternaria and Stemphylium isolates (Fig. 2). In comparing lesion development among isolates of the different Alternaria species-groups, no significant differences in pathogenicity could be detected among isolates in the alternata, tenuissima, or arborescens species-group, including the representative isolates (Fig. 2). Moreover, no significant differences in pathogenicity were evident between isolates recovered from asymptomatic and symptomatic pistachio tissue (data not shown). In contrast, average pathogenicity score for the isolates in the infectoria species-group was 1.5, significantly less than that of isolates in the other species-groups. Of the other fungi tested, only the Stemphylium isolates appeared to be pathogenic to pistachio, and were nearly as pathogenic as isolates of the alternata, tenuissima, and arborescens species-groups (Fig. 2). The Cladosporium, Epicoccum, and Fusarium isolates were only weakly pathogenic (Fig. 2). Results from the two separate experiments could not be combined due to lack of variance within certain treatments. 
However, the trends exhibited in both experiments were nearly identical.

Molecular characterization. For RAPD analysis of selected Alternaria isolates from pistachio (Table 3) and representative isolates, all random primers resulted in robust RAPD fragment patterns, and representative patterns for the isolates tested are provided (Fig. 3). Most amplification products were reproducible and a total of 136 RAPD fragments were scored. In some cases, minor fragments (i.e., those less intensely stained by ethidium bromide) were not reproducible and were not scored. What was immediately evident is that there existed little variation in RAPD fragment patterns among isolates of the alternata and tenuissima species-groups, including the representative species. There was also a high degree of pattern similarity among isolates of the arborescens species-group including the representative isolate, and these patterns were distinct from those of the alternata or tenuissima species-group. There was considerable RAPD fragment pattern variation among isolates in the infectoria group, although the patterns were quite distinct from those of the alternata, tenuissima, and arborescens species-groups.

For PCR-RFLP analysis, the IGS primers directed the amplification of a 2,500- to 2,700-bp fragment from all isolates tested (data not shown). All restriction enzymes resulted in robust digestion fragment patterns for the isolates tested, and representative patterns are provided (Fig. 4). All digestion products were reproducible and a total of 64 DNA fragments were scored. Results were very similar to those of the RAPD analysis in that few differences were evident among isolates of the alternata and tenuissima species-groups, among isolates of the arborescens species-group, and considerable variation among isolates of the infectoria species-group.
Cluster analysis of the RAPD and PCR-RFLP data sets individually (data not shown) revealed nearly identical results as the combined data set (Fig. 5). Three distinct clusters were evident: a cluster containing isolates of the infectoria species-group, a cluster containing isolates of the arborescens species-group, and a cluster containing isolates of the alternata and tenuissima speciesgroups. There was $88 \%$ similarity in RAPD and PCR-RFLP fragment patterns among isolates of the infectoria species-group, and $57 \%$ similarity between these isolates and the isolates of the alternata, tenuissima, and arborescens species-groups. There was $85 \%$ similarity in RAPD fragment patterns among isolates of the arborescens species-group, and 65\% similarity between these isolates and isolates of the alternata and tenuissima species-groups. Isolates of the alternata and tenuissima species-groups clustered together with $80 \%$ similarity in RAPD fragment patterns. Within this cluster, isolates of the alternata and tenuissima species-groups did not cluster separately, and isolates of the two species-groups were intermingled in several terminal clusters.

Sequence analysis of the ITS regions revealed $100 \%$ sequence identity among the eight pistachio isolates in the tenuissima species-group and the representative isolate, and five of the seven pistachio isolates in the alternata species-group and the representative isolate. Isolates A150 and A204, both members of the alternata species-group, had 1-nt substitution (A to C) compared with the remaining isolates of the alternata and tenuissima speciesgroups at position 152 in the ITS1 region. Sequence analysis also revealed $100 \%$ sequence identity among the 12 pistachio isolates in the arborescens species-group and the representative isolate. These isolates differed from the majority of isolates of the alternata and tenuissima species-groups by $1-n t$ deletion at position 181 in the ITS2 region. There was 98 to $99 \%$ sequence identity

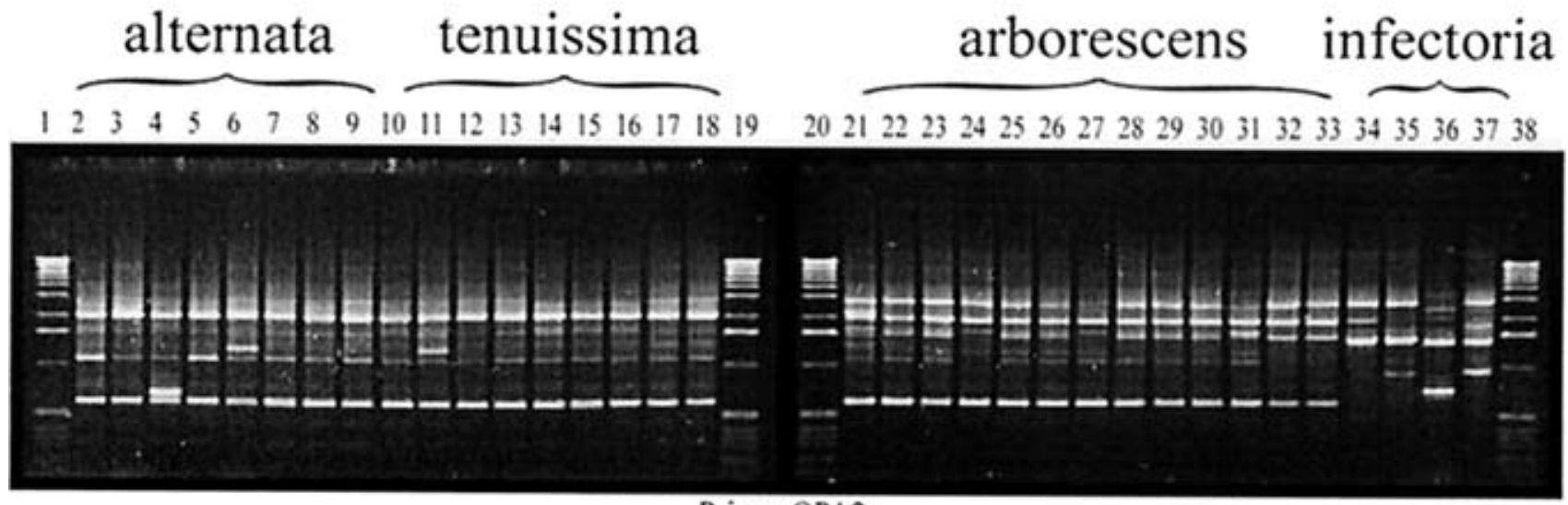

Primer OPA2

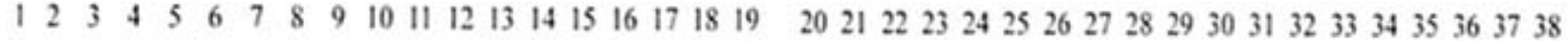

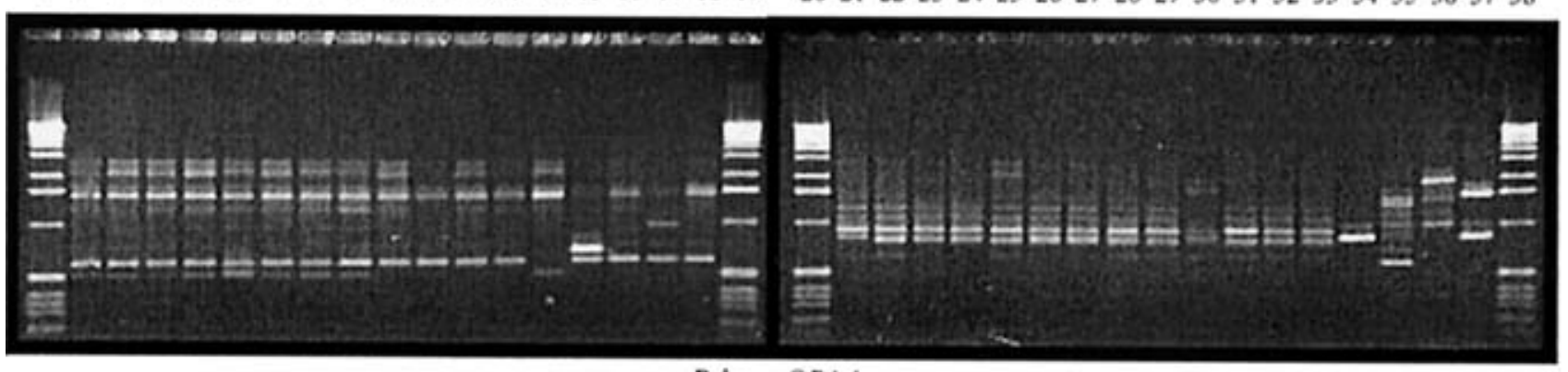

Primer OPA4

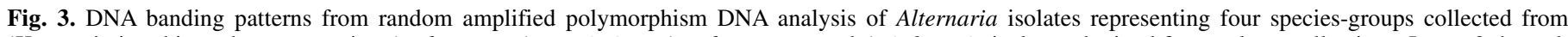

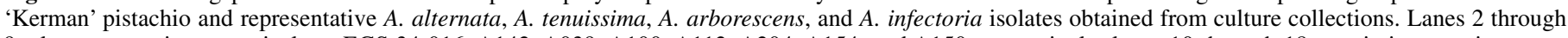

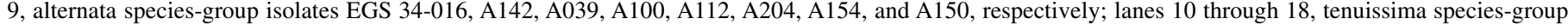

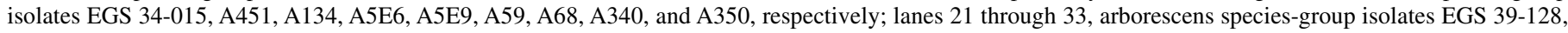

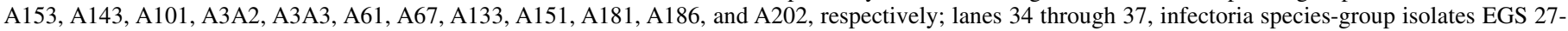
193, A65, A60, and A91, respectively. Lanes 1, 19, 20, and 38 contain the 1-kb DNA ladder (Gibco BRL, Gaithersburg, MD). 
among the three pistachio isolates of the infectoria species-group and the representative isolate. These isolates differed from isolates of the other species-groups by over $70 \mathrm{nts}$ in the ITS1 and ITS2 regions, including a 23-nt insertion in the ITS1 region. Sequences for the four representative Alternaria spp. were deposited as GenBank Accession Nos. AF347031, AF347032, AF347033, and AF347034 for EGS 34-016, EGS 34-015, EGS 39-128, and EGS 27-193, respectively.

Alignment of ITS sequences from pistachio isolates, the four representative Alternaria spp., and the GenBank accessions have been submitted to TreeBASE for review (submission SN721). In parsimony analysis, a heuristic search revealed 15 most parsimonious trees (length $=317, \mathrm{CI}=0.77, \mathrm{RI}=0.90$ ). All trees had near identical topology with the exception of species order within the $A$. porri clade, the $A$. radicina clade, and the $U$. botrytis clade (Fig. 6). Parsimony analysis revealed that isolates of the infectoria species-group were clearly distinct from isolates of the alternata, tenuissima, and arborescens species-groups, and other Alternaria spp., and formed a monophyletic clade. Isolates of the alternata, tenuissima, and arborescens species-groups also formed a monophyletic clade, although internal resolution of this clade was minimal due to the lack of sequence variation. Both monophyletic clades were well supported with bootstrap values of $100 \%$ (Fig. 6). Neighbor-joining analysis resulted in a phylogenetic tree with near identical topology as those from parsimony analysis (data not shown). As in parsimony analysis, the infectoria and the alternata/ tenuissima/arborescens monophyletic clades were well supported with bootstrap values of $100 \%$.

\section{DISCUSSION}

This work encompasses detailed studies on the diversity of smallspored catenulate Alternaria isolates recovered from pistachio orchards afflicted with Alternaria late blight disease. Studies were conducted on morphological, pathogenic, and molecular aspects. An important feature of this study was the precise definition of culture conditions for the characterization of colony morphology and sporulation habit among small-spored catenulate Alternaria spp. Details of Alternaria morphology vary under different culture conditions, which can be particularly misleading in descriptive and comparative work with small-spored catenulate species (29). Thus, the reproducibility of any study on the morphological diversity of these species will be most fully realized only by strict adherence to the culture conditions described.

For the characterization of colony morphology, this study revealed that incubation of single-spored colonies at $22^{\circ} \mathrm{C}$ in darkness on PDA resulted in diagnostic features that could be used to differentiate among pistachio and representative isolates of the tenuissima, arborescens, infectoria, and, in most cases, the alternata species-group. Previous work by Andersen et al. (1) and Andersen and Thrane (2) revealed that incubation in darkness on DRYES agar also permitted differentiation of A. alternata, A. gaisen, and A. longipes, and A. infectoria based upon colony characteristics. Although the media used in this study and those of Andersen were different, both were high in carbohydrate content. The use of rich media promotes vegetative growth of small-spored catenulate Alternaria spp. with a concomitant reduction in sporulating hyphae (29). The incubation of cultures in darkness, performed in both of these studies, further promotes vegetative growth while restricting sporulation. Moreover, colonies composed primarily of vegetative hyphae reveal much more variation in color and texture among small-spored catenulate Alternaria spp. than colonies composed primarily of strongly sporulating hyphae. Thus, differences in characteristics of colony morphology are most evident when colonies are grown on rich media in darkness.

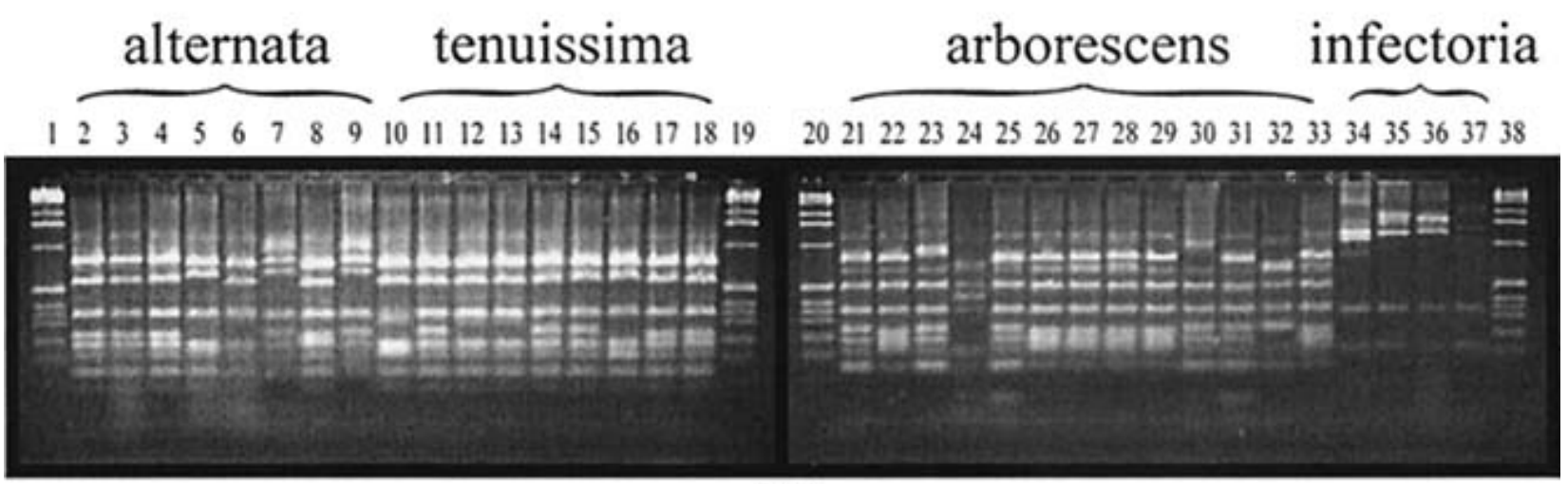

Rsal

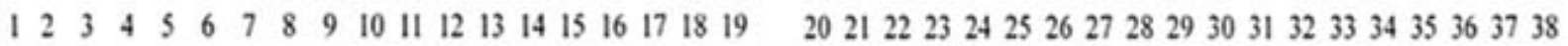

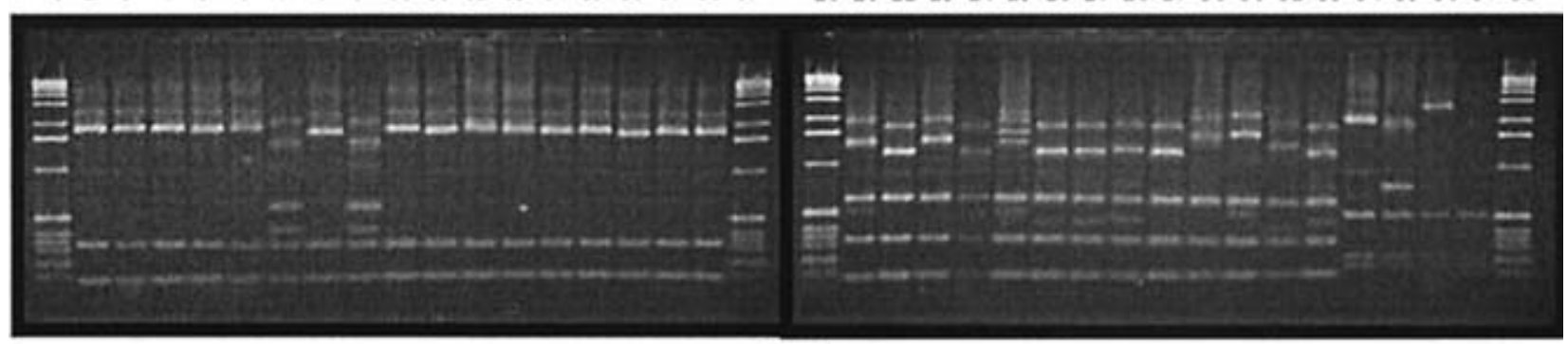

Mbol

Fig. 4. DNA banding patterns from restriction digests of Alternaria isolates representing four species-groups collected from 'Kerman' pistachio and representative A. alternata, A. tenuissima, A. arborescens, and A. infectoria isolates obtained from culture collections. Lanes 2 through 9 , alternata species-group isolates EGS 34-016, A142, A039, A100, A112, A204, A154, and A150, respectively; lanes 10 through 18, tenuissima species-group isolates EGS 34-015, A451, A134, A5E6, A5E9, A59, A68, A340, and A350, respectively; lanes 21 through 33, arborescens species-group isolates EGS 39-128, A153, A143, A101, A3A2, A3A3, A61, A67, A133, A151, A181, A186, and A202, respectively; lanes 34 through 37, infectoria species-group isolates EGS 27-193, A65, A60, and A91, respectively. Lanes 1, 19, 20, and 38 contain the 1-kb DNA ladder (Gibco BRL, Gaithersburg, MD). 
In contrast, for characterization of sporulation habit, nutritionally weak media and lighted incubation were used. This study precisely defines culture parameters of medium, temperature, light source, photoperiod, and light intensity, and all incubation was carried out in a growth chamber that maintained temperature and light parameters within narrow limits and excluded external environmental factors (e.g., ambient laboratory light and temperature fluctuations). Previous work by Simmons (29) has defined culture parameters of medium, temperature, light source, and photoperiod, but not the parameter of light intensity (lux), which is influenced by a number of factors including the type of lighting used, number and size of bulbs, distance from light source, and surrounding reflective surfaces. Our experience is that this is a critical parameter that must be specifically defined. The culture of isolates under defined conditions of light source and photoperiod may result in weak and nondiagnostic sporulation if sufficient light intensity is not provided, which will hamper the ability of the taxonomist to reproduce results of other studies and likely lead to incorrect identification of taxa.

Simmons also defined the use of potato-carrot agar (PCA) to culture small-spored catenulate Alternaria spp. for identification $(29,33)$. We have found that the use of $0.05 \times$ PDA has several advantages over the use of PCA. First, the density of conidiophores on $0.05 \times \mathrm{PDA}$ is much less than that on PCA, allowing for clear observation of typical conidiophores and accompanying conidial chains individually in most areas of the colony without excessive entanglement of conidial chains from adjacent conidiophores. Secondly, the production of $0.05 \times$ PDA from commercially available Difco PDA resulted in greater batch-to-batch uniformity of media, based upon characteristics of media color and particulate content, compared with the noncommercial formulation of PCA prepared from locally procured produce. Perhaps more importantly, potato and carrot obtained from different sources can vary significantly in terms of carbohydrate content and biochemical characteristics depending on cultivar and growing conditions $(23,34)$, which can affect the nutritional content of media prepared from them. The potatoes used in Difco PDA are of a single cultivar produced from one location under contract with a single source (D. Sibiski, Difco technical representative, personal communication). This fact, coupled with the implementation of quality specification and quality control programs inherent in most modern manufacturing facilities, would increase batch-to-batch uniformity of media, which results in more consistent development of conidia and sporulation characteristics specific for each isolate. It is important to note that conidia and sporulation characteristics of the representative isolates produced on $0.05 \times$ PDA were very similar to those produced on PCA as described by Simmons, which supports the use of $0.05 \times$ PDA in comparative studies. However, to further advance the robustness and reproducibility of morphological descriptions, the development of a chemically defined medium suitable for the sporulation of Alternaria spp. would be beneficial.

A second important feature of this study is that comparisons were made between Alternaria isolates recovered from pistachio and four representative small-spored catenulate Alternaria spp., which typify previously described Alternaria species-groups. Four morphologically distinct types of Alternaria were recovered from pistachio orchards based on characteristics of colony and sporulation apparatus. Although minor differences were apparent among isolates within each group, such as shade differences in colony color and slight differences in the degree of branching of the conidial chains, these four groups correlated very well with the four representative species included in this study for comparative purposes. The fact that all four of these groups were recovered in

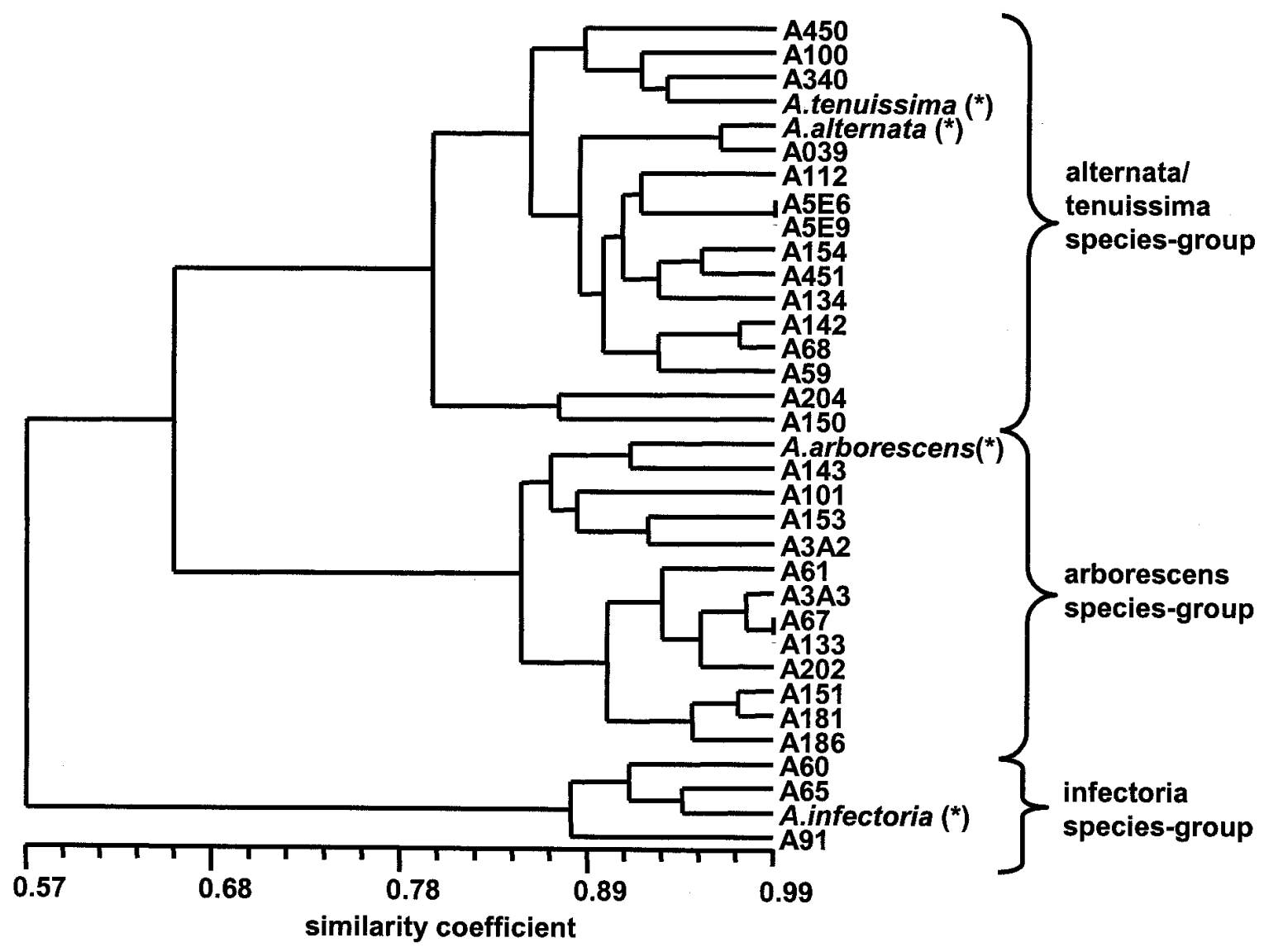

Fig. 5. Cluster analysis of combined data matrices from random amplified polymorphism DNA and polymerase chain reaction restriction fragment length polymorphism analysis of Alternaria isolates representing four species-groups collected from 'Kerman' pistachio and representative A. alternata, A. tenuissima, A. arborescens, and A. infectoria isolates obtained from culture collections $(*)$. 
all orchards, at all times of the year, and from all pistachio tissues including active late blight lesions, reveals that a complex of related fungi is associated with Alternaria late blight of pistachio.

Pathogenicity tests conducted on wounded pistachio leaves revealed that isolates from three of the four groups recovered from pistachio were pathogenic to pistachio. Isolates from the infectoria species-group, which were the least common of the isolates recovered, were essentially nonpathogenic, as were most of the saprobic fungi. Supporting these findings, previous work with Alternaria isolates recovered from pistachio also found three molecularly distinct groups of Alternaria isolates that were pathogenic in wounded leaf assays, although concurrent morphological characterization of isolates was not performed (4). Pathogenicity tests conducted on unwounded pistachio leaves did not result in substantial lesion development for any of the isolates tested, which may suggest that the conditions for penetration and infection of unwounded leaves may not have been optimized in our pathogenicity tests or that the leaves used in these assays were not optimally susceptible to infection. However, ONFIT analysis of apparently unwounded pistachio nuts and leaves collected in early and midseason nearly always recovered Alternaria isolates (22), which indicates that penetration and infection of pistachio tissue is a common occurrence and not significantly constrained by variation in environment or tissue susceptibility. In the field, these

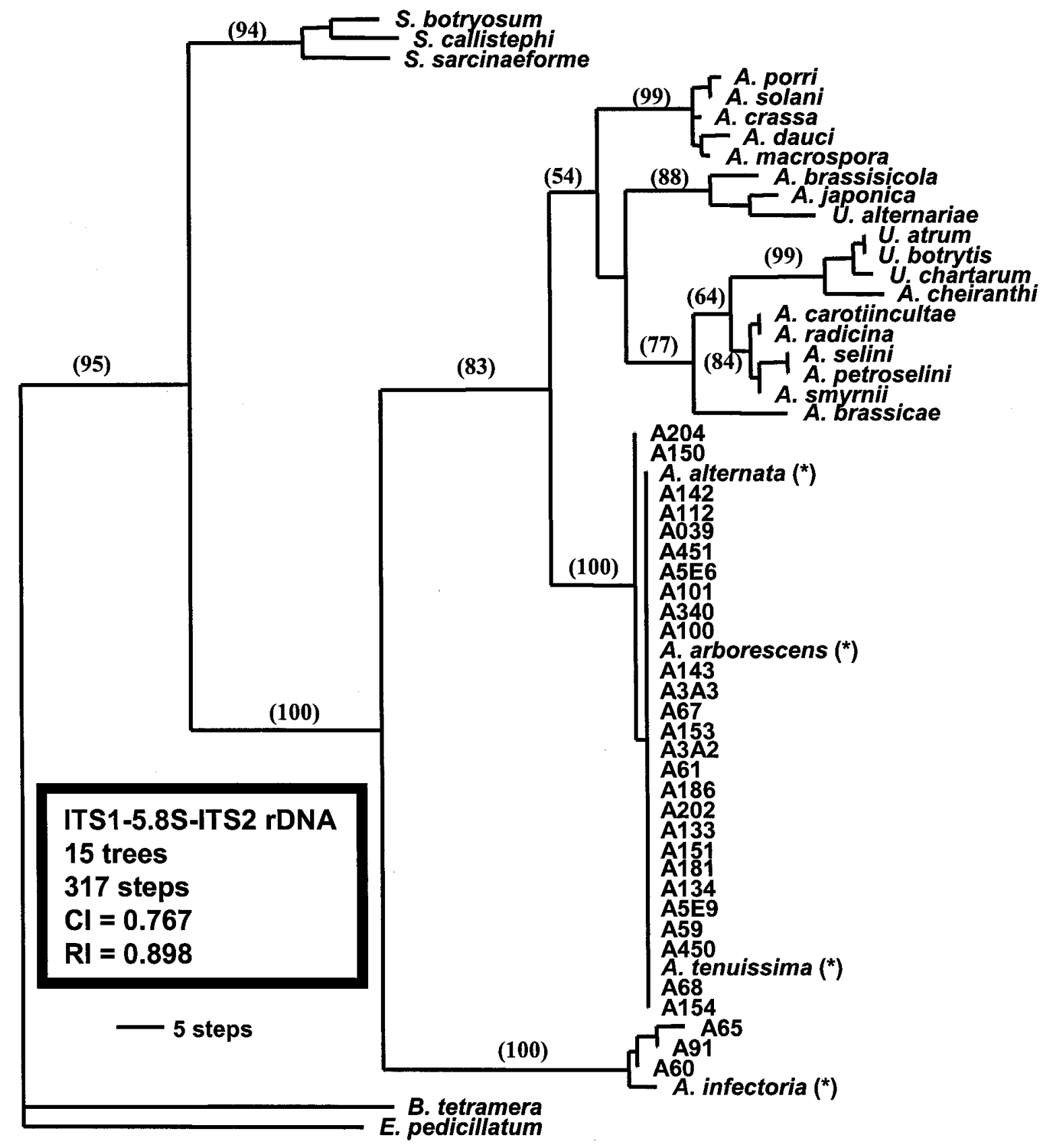

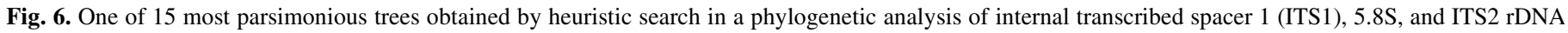

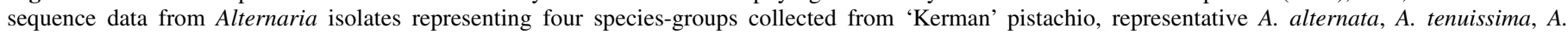

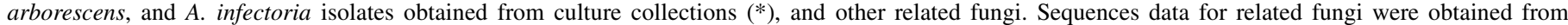

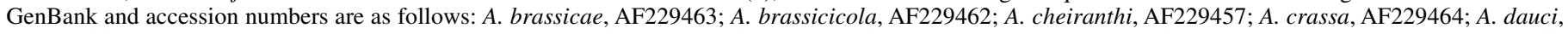

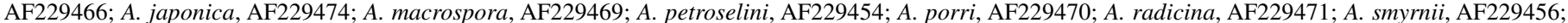

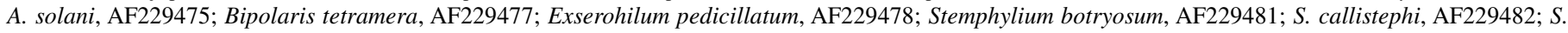

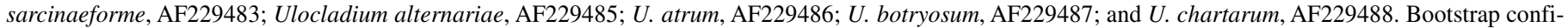
dence measures greater than $50 \%$ from 1,000 bootstrap replicates are indicated in parentheses. CI $=$ consistency index and RI $=$ retention index. 
infections are generally quiescent and it is only late in the season immediately before and following harvest that typical late blight symptoms begin to develop. This suggests that there may be late season physiological changes in pistachio that predispose tissue to disease development. Taking into account that penetration of pistachio tissue by Alternaria spp. is a common occurrence, the fact that lesion development occurs more readily and more predictably on wounded than unwounded leaves suggests that there may also be changes in the physiology of leaves following wounding that predispose leaves to lesion development.

The finding that the representative isolates of A. alternata, A. tenuissima, and $A$. arborescens, which were not originally recovered from pistachio, were also pathogenic indicates that hostspecific toxins may not be involved in pathogenicity. However, typical late blight symptoms include large chlorotic halos surrounding the developing lesions, which does suggest the presence of a phytotoxin. Considering the fact that many Alternaria spp. produce a number of toxins that are not host specific $(26,28)$, it cannot be concluded that phytotoxins are not involved in some aspect of pathogenicity. Stemphylium spp. also produce a number of phytotoxins that are not host specific $(5,12)$, and the Stemphylium isolates used in this study (isolated originally from pistachio leaf lesions) were the only other non-Alternaria fungi that were pathogenic in the wounded leaf assays.

The finding of a complex of Alternaria taxa pathogenic to a particular host is not unique to Alternaria-caused disease of pistachio because other research has documented similar findings regarding Alternaria-caused disease of pear, citrus, and almond $(31,33,36)$. In these studies, a varied assemblage of isolates with characteristics similar to those of the alternata, tenuissima, or arborescens species-groups were recovered from diseased tissue and found to be pathogenic on the respective host. Much of the variation in sporulation apparatus described among the various Alternaria isolates/species in all three studies was similar to the range of variation exhibited among Alternaria isolates from pistachio. The diagnostic key used in this study to characterize Alternaria isolates from pistachio into species-groups will be an important tool for future research on Alternaria late blight of pistachio. Although this key does not utilize all morphological characters previously attributed to each species-groups, it does utilize important characteristics of the sporulation apparatus that most simply separate members of each group, including representative cultures. Considering the common occurrence of small-spored catenulate Alternaria in agricultural systems, this key may likely have utility in assessing diversity of these taxa in other crops as well.

A third important feature of this study is that molecular characterization was based upon three different data sets: RAPD analysis, which characterizes random priming sites across the entire genome; PCR-RFLP analysis of nuclear IGS rDNA, which characterizes restriction sites within the highly variable IGS region; and sequence analysis of the highly variable ITS region. Regarding RAPD analysis, the potential of comigrating fragments not being homologous limits the utility of this fingerprinting technique in robust phylogenetic reconstruction $(6,35)$. To a lesser extent, the same can be said of RFLP techniques (37). If, however, the results of these analyses are corroborated with results of more rigorous methods of phylogenetic reconstruction, such as sequence analysis, the utility of fingerprinting techniques in assessing genetic relatedness would be enhanced.

In these studies, RAPD analysis revealed that isolates of the arborescens species-group are molecularly distinct from isolates of the alternata and tenuissima species-groups. Simmons and Roberts were first to recognize the distinct sporulation pattern of this group of fungi (33). Roberts et al. later revealed that isolates of the arborescens species-group are molecularly distinct from other small-spored catenulate species based upon variation in RAPD fingerprint patterns and that there are two distinct subgroups within a larger arborescens species-group (25), which is in agreement with our study. However, results of RAPD analyses conducted in this study revealed that isolates of the alternata and tenuissima species-groups did not separate into separate clades during cluster analysis, whereas they did separate in the study by Roberts et al. (25). In addition, these results clearly place isolates of the infectoria species-group in a distinct cluster from isolates in the alternata, tenuissima, and arborescens species-group, whereas in the study by Roberts et al. (25), the isolates in the infectoria species-group were placed within a clade containing isolates from the alternata and tenuissima species-groups. These different results may be explained by considering the differences in RAPD protocol between the two studies, particularly in the thermal cycles of the PCR, which can have a significant effect in the generation of RAPD fragments. However, our results are also supported by PCR-RFLP data, an independent data set derived from analyses of the nuclear IGS region.

ITS sequence analysis also supported results from both RAPD and PCR-RFLP analyses in that (i) the isolates in the infectoria species-group were distantly related to isolates in the arborescens, tenuissima, and alternata species-groups; (ii) the isolates in the arborescens species-group were distinct from isolates in the alternata and tenuissima species-group (1-nt deletion); and (iii) the isolates of the alternata and tenuissima species-groups did not separate into distinct clades. Two isolates of the alternata speciesgroup, A150 and A204, varied from other isolates of the alternata and tenuissima species-group by 1-nt substitution. Considering the minimal variation in ITS sequences among small-spored catenulate Alternaria spp. in general, it may be suggested that this region is inappropriate for taxonomic resolution of these species. However, previous research has supported the use of ITS sequence analysis in resolving the genus Alternaria into species-groups that correlate with morphology, and differentiating among closely related species within groups (21). Moreover, the amount of ITS sequence divergence among isolates of the alternata, tenuissima, and arborescens species-groups ( 1 to $2 \mathrm{nt}$ ) is less than that exhibited among isolates within the porri species-group ( 2 to $6 \mathrm{nt}$ ), which includes several species that have been considered formae speciales of a single species by some researchers $(8,18)$. Nonetheless, the development of molecular data sets based upon other genetic regions will likely be necessary to fully evaluate the utility of the ITS region in resolving relationships among Alternaria taxa.

The finding of several distinct morphological types of smallspored catenulate Alternaria associated with pistachio in this work and with pears, citrus, and almond in other work $(31,33,36)$ reveals that this complex of fungi may be commonly encountered. We have encountered this same fungal complex in isolations from leaf spots on carrot and tomato as well (B. M. Pryor, unpublished data). The fact that these fungi can be found associated with foliar disease symptoms on a variety of hosts suggests that they occupy the same, or nearly the same, ecological niche. If, in fact, these fungi occupy a similar ecological niche and represent a closely related monophyletic group (excluding the infectoria speciesgroup), the occurrence of morphological variation is most interesting. Before definitive species boundaries can be constructed for this group of closely related taxa that incorporates both morphological and molecular characteristics, it will be necessary to first understand the ecological and genetic basis for the development and maintenance of morphological variation. These future studies will provide the necessary background in the development of a taxonomic system of species, subspecies, varieties, or forms that may more accurately describe relationships among small-spored catenulate Alternaria.

\section{ACKNOWLEDGMENTS}

This work was partially supported by the California Pistachio Commission and the College of Agricultural and Environmental Sciences, University of California, Davis. 


\section{LITERATURE CITED}

1. Andersen, B., Krøger, E., and Roberts, R. G. 2001. Chemical and morphological segregation of Alternaria alternata, A. gaisen, and A. longipes. Mycol. Res. 105:291-299.

2. Andersen, B., and Thrane, U. 1996. Differentiation of Alternaria infectoria and Alternaria alternata based on morphology, metabolite profiles, and cultural characteristics. Can. J. Microbiol. 42:685-689.

3. Appel, D. J., and Gordon, T. R. 1996. Relationships among pathogenic and nonpathogenic isolates of Fusarium oxysporum based on the partial sequence of the intergenic spacer region of the ribosomal DNA. Mol. Plant-Microbe Interact. 9:125-138.

4. Aradhya, M. K., Chan, H. M., and Parfitt, D. E. 2001. Genetic variability in the pistachio late blight fungus, Alternaria alternata. Mycol. Res. 105:300-306.

5. Barash, I., Karr, A. L., Jr., and Strobel, G. A. 1975. Isolation and characterization of stemphylin, a chromone glucoside from Stemphylium botryosum. Plant Physiol. 55:646-651.

6. Black, I. W. C. 1993. PCR with arbitrary primers: Approach with care. Insect Mol. Biol. 2:1-6.

7. Corazza, L., and Aranzato, D. 1986. Alternaria alternata (Fries) Keissler su pistachio in Italia. (In Italian.) L' Informatore Agrario 25:73-75.

8. Joly, P. 1964. Le Genre Alternaria. Encyclopedie Mycologique. XXXIII. P. Lechevalier, Paris.

9. Kuninaga, S., and Yokusawa, R. 1987. Studies on the taxonomy of plant pathogenic fungi by a comparison of DNA homology. I. Genetic relatedness among species in the genus Alternaria. (In Japanese.) Ann. Phytopathol. Soc. Jpn. 53:368-369.

10. Kusaba, M., and Tsuge, T. 1994. Nuclear ribosomal DNA variation and pathogenic specialization in Alternaria fungi known to produce hostspecific toxins. Appl. Environ. Microbiol. 60:3055-3062.

11. Kusaba, M., and Tsuge, T. 1995. Phylogeny of Alternaria fungi known to produce host-specific toxins on the basis of variation in internal transcribed spacers of ribosomal DNA. Curr. Genet. 28:491-498.

12. Manulis, S., Netzer, D., and Barash, I. 1986. Structure-activity relationships as inferred from comparative phytotoxicity of stemphyloxins and betaenones. J. Phytopathol. 115:283-287.

13. Michailides, T. J., and Morgan, D. P. 1993. Principles for the control of Alternaria late blight of pistachio caused by Alternaria alternata in California. Pages 56-63 in: Proc. GREMPA Meeting-Pistachio, 9th. T. Caruso, E. Barone, and F. Sottile, eds. Bront, Sciacca, Italy.

14. Michailides, T. J., Morgan, D. P., Doster, M. A., and Kolliker, R. 1994. Biology, epidemiology, and control of Alternaria and Aspergillus blights of pistachio, and effects of these diseases on nut quality. Pages 49-56 in: Calif. Pistachio Industry Annu. Rep. Crop Year 1993/94, Fresno.

15. Michailides, T. J., Morgan, D. P., and Felts, D. 2000. Detection and significance of symptomless latent infection of Monilinia fructicola in California stone fruits. (Abstr.) Phytopathology 90(suppl.):S53.

16. Michailides, T. J., Morgan, D. P., Felts, D., and Ribiero, B. 1997. Monitoring and prediction of Alternaria late blight of pistachio and effect of fruit load on the disease. Pages 111-119 in: Calif. Pistachio Industry Annu. Rep. Crop Year 1996/97, Fresno.

17. Misaghi, I. J., Grogan, R. G., Duniway, J. M., and Kimble, K. A. 1978. Influence of environmental and culture media on spore morphology of Alternaria alternata. Phytopathology 68:29-34.

18. Neergaard, P. 1945. Danish Species of Alternaria and Stemphylium. Oxford University Press, London.

19. Nishimura, S., and Kohmato, K. 1983. Host-specific toxins and chemical structures from Alternaria species. Annu. Rev. Phytopathol.
21:87-116

20. Nobles, M. K. 1948. Studies in forest pathology. VI. Identification of cultures of wood-rotting fungi. Can. J. Res. 26:281-431.

21. Pryor, B. M., and Gilbertson, R. L. 2000. Molecular phylogenetic relationships amongst Alternaria species and related fungi based upon analysis of nuclear ITS and mt SSU rDNA sequences. Mycol. Res. 104: 1312-1321.

22. Pryor, B. M., Morgan, D., Felts, D., and Michailides, T. 2000. Environmental parameters affecting the progress of Alternaria late blight development. Pages 231-242 in: Calif. Pistachio Industry Annu. Rep. Crop Year 1999/2000, Fresno.

23. Putz, B. 1976. The effect of agronomic factors on potato tuber reducing sugar content. 1. The effect of year, site, and cultivar. Kartoffelbau 27: 230-231

24. Ridgway, R. 1912. Color Standards and Color Nomenclature. Published by the Author. Washington, DC.

25. Roberts, R. G., Reymond, S. T., and Andersen, B. 2000. RAPD fragment pattern analysis and morphological segregation of small-spored Alternaria species and species groups. Mycol. Res. 104:151-160.

26. Rotem, J. 1994. The Genus Alternaria: Biology, Epidemiology, and Pathogenicity. The American Phytopathological Society, St. Paul, MN.

27. Sambrook, J., Fritsch, E. F., and Maniatis, T. 1989. Molecular Cloning: A Laboratory Manual. Cold Spring Harbor Laboratory, Cold Spring Harbor, NY.

28. Scheffer, R. P. 1992. Ecological and evolutionary roles of toxins from Alternaria species pathogenic to plants. Pages 101-122 in: Alternaria Biology, Plant Diseases and Metabolites. J. Chelkowski and A. Visconti, eds. Elsevier Science Publishers, Amsterdam.

29. Simmons, E. G. 1992. Alternaria taxonomy: Current status, viewpoint, challenge. Pages 1-35 in: Alternaria Biology, Plant Diseases and Metabolites. J. Chelkowski and A. Visconti, eds. Elsevier Science Publishers, Amsterdam.

30. Simmons, E. G. 1995. Alternaria themes and variations (112-144). Mycotaxon 55:55-163.

31. Simmons, E. G. 1999. Alternaria themes and variations (226-235): Classification of citrus pathogens. Mycotaxon 70:263-323.

32. Simmons, E. G. 1999. Alternaria themes and variations (236-243): Hostspecific toxin producers. Mycotaxon 70:325-369.

33. Simmons, E. G., and Roberts, R. G. 1993. Alternaria themes and variations (73). Mycotaxon 48:109-140.

34. Skupinova, S. 1997. The effect of cultivar on the nitrate content of carrot juice. Zahradnictvi 24:25-27.

35. Smith, J. J., Scott-Craig, J. S., Leadbetter, J. R., Bush, G. L., Roberts, D. L., and Fulbright, D. W. 1994. Characterization of random amplified polymorphic DNA (RAPD) products from Xanthomonas campestris and some comments on the use of RAPD products in phylogenetic analysis. Mol. Phylogenet. Evol. 3:135-145.

36. Teviotdale, B. L., Viveros, M., Pryor, B. M., and Adaskaveg, J. E. 2001. First report of Alternaria leaf spot of almond caused by species in the Alternaria alternata complex in California. Plant Dis. 85:558.

37. Upholt, W. B. 1977. Estimation of DNA sequence divergence from comparison of restriction endonuclease digests. Nucleic Acids Res. 4:12571265.

38. Wasfy, E. H., Ibrahim, I. A., and Elarosi, H. M. 1974. New Alternaria disease of pistachio in Egypt. Phytopathol. Mediterr. 13:110-111.

39. White, T. J., Bruns, T., Lee, S., and Taylor, J. 1990. Amplification and direct sequencing of fungal ribosomal RNA genes for phylogenetics. Pages 315-322 in: PCR Protocols: A Guide to Methods and Applications. Academic Press, London. 